\title{
Percutaneous Endoscopic Gastrostomy Tube Removal for Patients With Advanced Dementia: Case Series Study
}

\author{
Yukari Hattori ${ }^{1}$, Taro Kojima ${ }^{1}$, Hiroaki Komura ${ }^{2}$, Nobuyuki Ura ${ }^{2}$, Masahiro Akishita ${ }^{1}$ \\ ${ }^{1}$ Department of Geriatric Medicine, Graduate School of Medicine, The University of Tokyo, Tokyo, Japan \\ ${ }^{2}$ Sapporo Nishimaruyama Hospital, Sapporo, Japan
}

Corresponding Author:

Taro Kojima, MD, PhD

https://orcid.org/0000-0003-3857-5267

Department of Geriatric Medicine,

Graduate School of Medicine, The

University of Tokyo, 7-3-1 Hongo,

Bunkyo-ku, Tokyo 113-8655, Japan

E-mail: tkojima-tky@umin.ac.jp

Received: February 13, 2019

Revised: March 15, 2019

Accepted: March 21, 2019

\begin{abstract}
Background: Although the notion of percutaneous endoscopic gastrostomy (PEG) tube placement for patients with dementia has been changing, the number of cases of PEG placement remains high as Japan has become a super-aged society. However, there is insufficient research about the clinical course of dementia patients with PEG, especially regarding $P E G$ extubation after regaining full oral intake. This case series aimed to reveal the demographic data of patients who successfully underwent PEG extubation and to identify clinical factors that might help predict eventual resumption. Methods: This retrospective case series was identified in a private, community-based long-term care hospital in Sapporo, Japan. Inclusion criteria for the series were: 1) age, $\geq 75$ years, 2) diagnosis of any type of dementia, and 3) resumption of full oral intake after removal of PEG tubes. Results: Eight female patients were identified. Decreased oral intake was triggered by acute medical conditions, such as infectious enteritis. A trial of oral intake was initiated mostly by speech therapists. A majority of the patients ate pureed food. The patients aged $\geq 85$ years with advanced dementia could be weaned from PEG tubes. Conclusion: The series indicates that even patients with limited life expectancy could recover swallowing function by receiving appropriate guidance and care. Constant evaluation for swallowing function even after PEG insertion may be important for PEG extubation. (Ann Geriatr Med Res 2019;23:27-30)
\end{abstract}

Key Words: Deglutition disorders, Dementia, Gastrostomy

\section{INTRODUCTION}

Japan has become a super-aged society with the largest scale as well as the fastest speed worldwide. Consequently, malnutrition has emerged as a serious problem among the geriatric population due to impaired oral intake. Insertion of percutaneous endoscopic gastrostomy (PEG) tube is common for patients with dysphagia due to stroke and progressive degenerative neurological conditions, such as Parkinson's disease and dementia. ${ }^{1)}$

Compared to nasogastric tubes, PEG tubes are well tolerated among patients and reduce the burden on caregivers. Moreover, because advance care planning is still not fully established in Japan, family members often struggle to make a decision that may not reflect the patient's wishes. ${ }^{2)}$ Prior to making a decision on tube feeding, it is ideal to have a discussion with an interdisciplinary team comprising a physician, nurse, social worker, and caregiver. However, due to time constraints, physicians usually explain the choices (nasogastric tube feeding, PEG tube feeding, and total parenteral nutrition) to the family and await their decision in a short period. As a result, the number of cases of PEG tube placements increased in the early 2000s. ${ }^{3)}$

A review of studies on PEG tubes found no survival advantage with tube feeding, and no evidence of benefit in terms of nutritional status or pressure ulcer prevalence. ${ }^{4,5)}$ In Western countries, PEG tubes for patients with advanced dementia are considered futile; thus, the rate of tube feeding in nursing homes is low (0.9\% in Australia, $1.2 \%$ in Canada, and 5.4\% in the USA). ${ }^{4,6,7)}$ The notion of PEG tubes for patients with dementia has been changing in Japan. The Japanese Ministry of Health, Labour and Welfare assigned additional fee points for evaluation of swallowing function in 2014 and the Japan Geriatrics Society suggested thorough evaluation before insertion of PEG tubes in 2012. ${ }^{8)}$ However, the continued use of PEG tubes in dementia patients persists in Japan. The rate of PEG tube feeding is $8.3 \%$ among nursing homes, $6.0 \%$ among geriatric intermediate care facilities, and $26.2 \%$ among medical facilities. ${ }^{9)}$

It is important to note that some patients on PEG tube feeding recover their swallowing function and resume full oral intake in the clinical setting; however, little is known about the outcomes of PEG tube removal and factors affecting swallowing restoration in patients with 
advanced dementia. Two studies reported the rate of PEG tube removal in Japan as $1.7 \%$ and 6.5\%, respectively. ${ }^{10,11)}$ However, no studies have thus far explored patients who resume full oral intake after removal of PEG tubes.

Thus, this case series aimed to reveal the demographic data of patients who successfully underwent PEG extubation and to identify clinical factors that might help predict eventual resumption.

\section{MATERIALS AND METHODS}

This single-center case series was identified at Sapporo Nishimaruyama Hospital, Sapporo, Japan from January 2016 to May 2016. Sapporo Nishimaruyama Hospital is a 650-bed long-term care hospital. Inclusion criteria for the series were: 1) age, 75 years or older, 2) diagnosis of any type of dementia, and 3) resumption of full oral intake after removal of PEG tubes. Exclusion criteria were: 1) age, 74 years or younger and 2) insertion of PEG tube due to dysphagia caused by cerebrovascular disease. The researchers extracted the following data based on electronic medical records: age, gender, underlying diseases, type of dementia, and type of diet the patient consumed at the time of the study. In addition, the following patient data were collected from the inpatient unit notes composed by nurses, speech therapists, and doctors from the medical records: Clinical Dementia Rating, indication for placement of PEG tubes, type of evaluation (video fluoroscopy [VF] or video endoscopy [VE] prior to gastrostomy), length of time before PEG tube insertion, duration of PEG tube use, and who initiated trial of oral intake. The study was approved by the Institutional Research Ethics Committee of
Sapporo Nishimaruyama Hospital. Written informed consent was obtained from the next of kin of patients.

\section{RESULTS}

Eleven patients were identified, three of whom were excluded due to post-stroke dysphagia (Fig. 1). As a result, 8 patients were included in the study. None of the patients had the capacity to make decisions and there was no record of patients' advance directives.

The sociodemographic and clinical characteristics of the patients are presented in Table 1. The mean age was 90.1 years (standard deviation, 4.9) and all patients were females. Alzheimer's disease was the most common type of dementia (4 patients), followed by vascular dementia

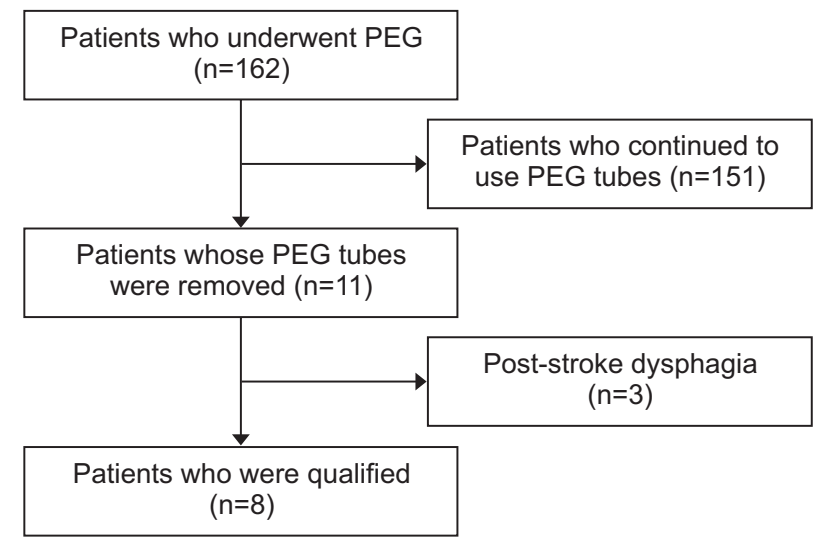

Fig. 1. Flow chart of patient enrollment in the study. PEG, percutaneous endoscopic gastrostomy.

Table 1. Demographic data of patients

\begin{tabular}{|c|c|c|c|c|c|c|c|c|c|}
\hline Age/sex & Comorbidity & $\begin{array}{l}\text { Type of } \\
\text { dementia }\end{array}$ & CDR & $\begin{array}{l}\text { Indications } \\
\text { for PEG }\end{array}$ & Evaluation & $\begin{array}{l}\text { Length } \\
\text { of time } \\
\text { before PEG } \\
\text { insertion }\end{array}$ & $\begin{array}{l}\text { Duration of } \\
\text { PEG use }\end{array}$ & $\begin{array}{l}\text { Initiation of } \\
\text { oral intake }\end{array}$ & $\begin{array}{l}\text { Diet } \\
\text { type }\end{array}$ \\
\hline \multirow[t]{3}{*}{$94 / \mathrm{F}$} & SSS & $\mathrm{AD}$ & 3 & $\begin{array}{l}\text { Infectious } \\
\text { gastroenteritis }\end{array}$ & No & $1 \mathrm{y}$ & $1 \mathrm{y}$ & - & Jelly \\
\hline & Chronic bronchitis & & & & & & & & \\
\hline & Femoral fracture & & & & & & & & \\
\hline $90 / \mathrm{F}$ & Hypertension & $\mathrm{AD}$ & 3 & Not identified & VF & $6 \mathrm{mo}$ & $13 \mathrm{mo}$ & Care worker & Jelly \\
\hline $86 / F$ & $\begin{array}{l}\text { Subdural } \\
\text { hematoma }\end{array}$ & $\begin{array}{c}\text { Mixed } \\
(\mathrm{AD} \text { and } \mathrm{VD})\end{array}$ & 3 & Pneumonia & VF & $6 \mathrm{mo}$ & $4 \mathrm{mo}$ & Nurse & Pureed \\
\hline $94 / F$ & Diabetes & $\mathrm{AD}$ & - & Femur fracture & No & $3 \mathrm{mo}$ & $3 \mathrm{mo}$ & ST & Pureed \\
\hline $98 / F$ & CHF, diabetes & DLB & 2 & Septic shock & VF & $4 \mathrm{mo}$ & $9 \mathrm{mo}$ & ST & Congee \\
\hline $83 / F$ & $\begin{array}{l}\text { Hypertension, } \\
\text { Epilepsy }\end{array}$ & VD & 2 & BPSD & ST & $1.5 \mathrm{y}$ & $15 \mathrm{mo}$ & MD & Jelly \\
\hline $89 / F$ & $\begin{array}{l}\text { Cerebral } \\
\text { hemorrhage } \\
\text { Hydrocephalus }\end{array}$ & VD & 3 & $\begin{array}{l}\text { Infectious } \\
\text { gastroenteritis }\end{array}$ & ST & $6 \mathrm{mo}$ & 3 y 10 mo & ST, nurse & Pureed \\
\hline $87 / F$ & $\begin{array}{l}\text { Atrial fibrillation } \\
\text { Ischemic stroke }\end{array}$ & VD & - & Femoral fracture & VF & $2 \mathrm{mo}$ & $13 \mathrm{mo}$ & - & Solid \\
\hline
\end{tabular}

CDR, Clinical Dementia Rating; PEG, percutaneous endoscopic gastrostomy; F, female; SSS, sick sinus syndrome; CHF, congestive heart failure; AD, Alzheimer's disease; VD, vascular dementia; DLB, dementia with Lewy bodies; BPSD, behavioral and psychological symptoms of dementia; VF, video fluoroscopic examination of swallowing; ST, speech therapist; MD, medical doctor; -, no record identified. 
(3 patients), and dementia with Lewy bodies (1 patient). A majority of the patients had a Clinical Dementia Rating of 2 or 3, indicative of advanced dementia. It is noteworthy that we evaluated the patients' functional status based on the scale that is widely used in Japanese long-term care hospitals referred to as "the scale for independence degree of daily living for the disabled elderly by the Japanese Ministry of Health, Labour and Welfare". In this scale, activities of daily living are classified into 4 levels (J, independent; A, quasi-bedridden; B, bedridden [lies in bed for much of the day, although the sitting position is possible]; and C: bedridden all day). ${ }^{12)}$ In our study, 6 out of 8 patients were in level B, indicating that they were bedridden. Decreased oral intake was triggered by acute medical conditions, such as pneumonia and infectious enteritis. For most patients ( 6 patients), 6 months elapsed prior to the insertion of PEG tubes. For 3 patients, a trial of oral intake was initiated by speech therapists. Six patients ate a nonsolid diet (pureed food).

\section{DISCUSSION}

The main aim of this study was to reveal demographic data of patients who successfully underwent PEG extubation and identify clinical factors to help predict eventual resumption among patients with advanced dementia. To our knowledge, there is insufficient research about the clinical course of dementia patients with PEG, especially regarding PEG extubation after regaining full oral intake. The patients aged $\geq 85$ years with advanced dementia could be weaned from PEG tubes, indicating that even patients with limited life expectancy could recover swallowing function by receiving appropriate guidance and care.

In clinical settings, VF or VE are performed to evaluate swallowing function. However, especially among patients with dementia, there are cases in which the results of VF and VE may be inaccurate due to an inappropriate environment. Therefore, although swallowing function may be intact, they might be misdiagnosed with dysphagia. In addition, before the Ministry of Health, Labour and Welfare assigned additional fee points for evaluation of swallowing function in 2014, patients could easily undergo gastrostomy without VF/VE evaluation. In other words, patients who could easily recover their swallowing function might have undergone PEG insertion. Comfort feeding by hand, in which patients receive frequent small amounts of food, sips of liquids, or oral feeding, ${ }^{13)}$ might be appropriate in these cases.

All patients in this study were females. The following underlying factors might account for the gender distribution of patients: Firstly, the patients with PEG were predominantly female (64\%) at the Nishimaruyama Hospital, and the 3:7 (male:female) ratio was close to those reported in other studies. ${ }^{10)}$ Secondly, the risk factors for poor survival in patients with dementia includes male gender ${ }^{14)}$; thus, more females tended to survive, which may explain the all-female composition our patient population.

Regarding the predictors of PEG extubation, no previous study evaluated PEG extubation among patients with dementia. One study evaluated patients who underwent PEG tube placement due to a cerebrovascular accident, progressive neurodegenerative disorders, and ear nose throat tumor, and indicated that having some oral intake at 3 and 6 months after PEG insertion were independent predictors of eventual PEG extubation. ${ }^{15)}$ A trial of oral intake should be encouraged at an early stage after PEG tube placement. It is noteworthy that the survival rate among patients with PEG tube placement is higher in Japan than in Western countries. ${ }^{14,16-18)}$ This means that not only is the evaluation of swallowing function necessary at the early stage, but constant evaluation should be performed for those patients with long-term PEG tube use. Among the patients in this case series, the duration of PEG tube placement varied from 3 months to 3 years, indicating that evaluation and intervention at any time could be effective for eventual PEG extubation.

Decreased oral intake due to an acute medical condition could be another predictor of PEG extubation. Patients with advanced dementia might recover reversible swallowing function by acquiring nutrients through PEG. A previous study showed that improvement of oral intake was noticed in 15\%-18\% of patients with advanced dementia. Moreover, two studies reported rates of PEG extubation of 1.7\% and 6.5\% among patients with PEG; this rate is close to that obtained in our study (5.3\%)..$^{19,20)}$ Thus, there could be patients whose PEG tubes remained in situ although their swallowing function had improved. Taken together, extended follow up by professionals, such as speech therapists, may play an important role in PEG extubation.

This study has some limitations. It was a retrospective single-center case series comprising a small sample size; a larger-scale multiple-center study is needed in the future. In addition, the future study should include patients who continue to use PEG and compare the two groups to elucidate factors that may be linked to PEG extubation.

This case series reveals the demographic data of patients with advanced dementia who successfully underwent PEG extubation, indicating that patients with the advanced dementia and including those aged $\geq 85$ years with PEG tubes in situ, may be able to return to full oral intake by receiving appropriate follow up and care. Constant evaluation of swallowing function even after PEG tube placement may play an important role in PEG extubation.

\section{CONFLICTS OF INTEREST DISCLOSURES}

The researchers claim no conflicts of interest.

\section{REFERENCES}

1. Role of PEG/PEJ in enteral feeding. American Society for Gastrointestinal Endoscopy. Gastrointest Endosc 1998;48:699-701. 
2. Hoefler JM. Making decisions about tube feeding for severely demented patients at the end of life: clinical, legal, and ethical considerations. Death Stud 2000;24:233-54.

3. Suzuki Y. Indication and problem of PEG feeding. Japanese Journal of Geriatrics 2012;49:126-9.

4. Sampson EL, Candy B, Jones L. Enteral tube feeding for older people with advanced dementia. Cochrane Database Syst Rev 2009;(2):CD007209.

5. Goldberg LS, Altman KW. The role of gastrostomy tube placement in advanced dementia with dysphagia: a critical review. Clin Interv Aging 2014;9:1733-9.

6. Australian Government Department of Health and Ageing (DoHA). Review of the aged care funding instrument. Canberra: Australian Government Department of Health; 2017.

7. Canadian Institute for Health Information. CCRS profile of residents in continuing care facilities 2012-2013. Ottawa: Canadian Institute for Health Information; 2013.

8. Ouchi Y, Toba K, Ohta K, Kai I, Shimizu T, Higuchi N, et al. Guidelines from the Japan Geriatrics Society for the decision-making processes in medical and long-term care for the elderly: focusing on the use of artificial hydration and nutrition. Geriatr Gerontol Int 2018;18:823-7.

9. Ministry of Health, Labour and Welfare. Survey of institutions and establishments for long-term care. Tokyo: Ministry of Health, Labour and Welfare; 2012.

10. Suzuki Y, Urashima M, Izumi M, Ito Y, Uchida N, Okada S, et al. The effects of percutaneous endoscopic gastrostomy on quality of life in patients with dementia. Gastroenterology Res 2012;5:10-20.

11. Yokohama S, Aoshima M, Koyama S, Hayashi K, Shindo J, Maruyama J. Possibility of oral feeding after induction of percutaneous endoscopic gastrostomy. J Gastroenterol Hepatol
2010;25:1227-31.

12. Ministry of Health, Labour and Welfare. The scale for independence degree of daily living for the disabled elderly. Tokyo: Ministry of Health, Labour and Welfare; 1992.

13. Arcand M. End-of-life issues in advanced dementia: Part 2: management of poor nutritional intake, dehydration, and pneumonia. Can Fam Physician 2015;61:337-41.

14. Brooke J, Ojo 0. Enteral nutrition in dementia: a systematic review. Nutrients 2015;7:2456-68.

15. Paramsothy S, Papadopoulos G, Mollison LC, Leong RW. Resumption of oral intake following percutaneous endoscopic gastrostomy. J Gastroenterol Hepatol 2009;24:1098-101.

16. Higaki F, Yokota 0, Ohishi M. Factors predictive of survival after percutaneous endoscopic gastrostomy in the elderly: is dementia really a risk factor? Am J Gastroenterol 2008;103:1011-6.

17. Ayman AR, Khoury T, Cohen J, Chen S, Yaari S, Daher S, et al. PEG insertion in patients with dementia does not improve nutritional status and has worse outcomes as compared with PEG insertion for other indications. J Clin Gastroenterol 2017;51:41720.

18. Schneider AS, Schettler A, Markowski A, Luettig B, Kaufmann B, Klamt S, et al. Complication and mortality rate after percutaneous endoscopic gastrostomy are low and indication-dependent. Scand J Gastroenterol 2014;49:891-8.

19. Suzuki Y, Tamez S, Murakami A, Taira A, Mizuhara A, Horiuchi A, et al. Survival of geriatric patients after percutaneous endoscopic gastrostomy in Japan. World J Gastroenterol 2010;16:5084-91.

20. Okuyama H, Mikami T, Kimura T, Urabe H, Takahashi T, Okabayashi S, et al. The actual conditions of patients with a gastrostomy in Japan. Ronen Shika Igaku 2013;28:352-60. 